\title{
Narrativas e memórias poéticas na educação infantil: possibilidades à docência
}

\author{
Narratives and poetic memories in early childhood education: \\ possibilities for teaching
}

\section{Narrativas y memorias poéticas en educación infantil: posibilidades para la docencia}

Lúcia de Mendonça Ribeiro'

https://orcid.org/0000-0003-0985-9228

Luciene dos Santos Silva ${ }^{2}$

https://orcid.org/0000-0002-1746-5096

Lucineide Ferreira da Silva ${ }^{3}$

https://orcid.org/0000-0003-0635-446X

Resumo: Este relato de experiência propõe refletir sobre uma situação desenvolvida na Educação Infantil com crianças pequenas, envolvendo Linguagens Expressivas. A proposta levou em conta as narrativas e experiências brincantes e culturais das crianças e de seus avós. Seus saberes, fazeres e valores culturais são considerados saberes formativos que enriquem os repertórios de crianças e adultos, transcendem um currículo previsto e promovem um novo olhar sobre a docência. A palavra artesania dialoga com as proposições do texto no sentido de que fazer é pensar. Assim, autores como Sennett (2013; 2020); Gobbato; Barbosa (2019); Formosinho (2019) e Rinaldi (20l2), entre outros, ajudam-nos a aprender em companhia. A escuta potente valorizou as narrativas e memórias dos sujeitos envolvidos ao construir redes de significados e possibilidades poéticas à docência e ao processo de aprendizagem e desenvolvimento infantil.

Palavras-chave: Educação Infantil. Linguagens Expressivas.

Abstract: This experience report proposes to reflect on an experience developed in Early Childhood Education with young children involving Expressive Languages. The proposal considered the narratives and playful and cultural experiences of children and their grandparents. Their knowledge, practices and cultural values are

\footnotetext{
' Doutora em Educação. Pedagoga/professora efetiva da Educação Infantil na rede pública de Maceió, Alagoas. Email: lucia_0707@yahoo.com.br

2 Concluinte do curso de Pedagogia da Universidade Federal de Alagoas (UFAL). E-mail: lucienedss869l@gmail.com

${ }^{3}$ Especialista em Psicopedagogia. Pedagoga/professora efetiva e coordenadora da Educação Infantil na rede pública de Maceió, Alagoas. E-mail: edienicul@hotmail.com
}

Olhar de professor, Ponta Grossa, v. 24, p. I-2I, e-17523.083, 202 I.

Disponível em <https://revistas2.uepg.br/index.php/olhardeprofessor> 
considered formative knowledge that enrich the repertoires of children and adults, transcend a predicted curriculum and promote a new perspective on teaching. The word artesania dialogues with the text's propositions in the sense that doing is thinking. Thus, authors like Sennett (20I3; 2020); Gobbato;Barbosa (2019); Formosinho (2019), Rinaldi (2012) and others help us to learn in company. Potent listening enhanced the narratives and memories of the subjects involved when building networks of meanings and poetic possibilities for teaching and the process of learning and child development.

Keywords: Early Childhood Education. Expressive Languages. Teaching.

Resumen: Este relato de experiencia propone reflexionar sobre una experiencia desarrollada en Educación Infantil con niños pequeños involucrando Lenguajes Expresivos. La propuesta consideró las narrativas y experiencias lúdicas y culturales de los niños y sus abuelos. Sus conocimientos, prácticas y valores culturales se consideran conocimientos formativos que enriquecen los repertorios de niños y adultos, trascienden un plan de estudios previsto y promueven una nueva perspectiva de la enseñanza. La palabra artesania dialoga con las proposiciones del texto en el sentido de que hacer es pensar. Así, autores como Sennett (2013; 2020); Gobbato; Barbosa (2019); Formosinho (2019), Rinaldi (20I2) y otros nos ayudan a aprender en compañía. La escucha potente potenció las narrativas y los recuerdos de los sujetos involucrados al construir redes de significados y posibilidades poéticas para la enseñanza y el proceso de aprendizaje y desarrollo infantil.

Palabras-clave: Educación Infantil. Lenguajes expresivos. Enseñando.

\section{Introdução}

Por meio das interações e da brincadeira, as crianças contam-nos suas vivências cheias de sentido e imaginação. Elas nos apresentam saberes e fazeres culturais próprios de suas infâncias, famílias e comunidades, mediante um diálogo curioso entre as múltiplas linguagens que lhes são apresentadas e as ações de educar e cuidar. A Educação Infantil (El) - primeira etapa da Educação Básica - tem modos e tempos distintos de outras etapas do sistema educacional, organizando-se por relações cotidianas, considerando singularidades que necessitam ser acolhidas, conhecidas, revisitadas e respeitadas. Essas relações ampliam as experiências das crianças e dos profissionais da Educação, convidando-nos, diariamente, a um mergulho profundo ao encontro do encantamento.

Neste sentido, o texto propõe uma reflexão acerca de uma experiência que envolveu as linguagens da Arte entre crianças pequenas (4 anos) na Educação Infantil da rede pública alagoana. A proposta considerou experiências brincantes e culturais dos avós das crianças, narradas por eles e pelos netos, alunos do Centro Municipal de Educação Infantil (CMEI), tornando nossas tardes surpreendentes. Estes saberes e fazeres culturais e singulares enriqueceram repertórios de crianças e adultos e promoveram um novo olhar e possibilidades outras à docência e à didática - um pensar prazeroso que possibilitou a todos fazer e pensar juntos. Os saberes emergentes dos relatos dos avós das crianças sobre suas experiências brincantes de infância levaram-nos a refletir sobre a necessidade de ressignificar o planejamento, valorizando a escuta.

O conceito de artesania problematizado por Richard Sennett foi provocador no sentido de que entendêssemos que fazer é pensar. Assim, fomos convidadas a rever uma compreensão de tempo e um modo de fazer que vem dialogando com o trabalho pedagógico na escola e, do mesmo modo, 
reconsiderar a percepção que temos sobre outros saberes, modos, materiais e suas materialidades e tempos que transcendem um currículo previsto.

A escuta atenta e sensível valorizou as narrativas e memórias infantis dos sujeitos envolvidos - crianças, famílias e profissionais da Educação -, por meio de experiências com as linguagens da Arte, portanto, linguagens expressivas ${ }^{4}$, recebendo maior atenção as escolhas e os interesses infantis. Destacaram-se a modelagem, a escultura, a pintura e a fotografia; assim, houve construção e ampliação de uma rede de significados e possibilidades poéticas à docência e ao processo de aprendizagem e desenvolvimento infantil.

Horizontes legais, conceituais e práticos da educação infantil

O cotidiano educativo é um reino de possibilidades. A vida é um reino de possibilidades. Não façamos dele e dela uma dura canção, repetitiva, amarrada, mecânica. Transformemos essa possibilidade num hino à invenção, lembrando sempre que a todo momento precisamos sonhar para criar (OSTETTO, 2012, p. 94).

Ao nos apropriarmos da narrativa da autora para abrir este texto, percebemos o quanto ainda temos que caminhar para propor às nossas crianças, na Educação Infantil (EI), o direito de sonhar. Tal constatação exige que problematizemos a legislação, os estudos e as pesquisas, nossos planejamentos e metodologias, na intencionalidade de potencializarmos as discussões, os conceitos e as teorias que embasam nossa compreensão prática.

Considerando os avanços, a docência e a didática na Educação Infantil ainda necessitam subverter a lógica de currículos e planejamentos rígidos e ideais, pois não compartilham do imprevisível, do encantamento e do inusitado, tampouco de uma ideia de tempo não prescrito.

Outras concepções de planejamento, tempos, modos de ser e estar, potencialidades dos materiais, suas materialidades e espaços carecem de ser questionadas e investigadas para que o exercício de nossa docência possa oportunizar experiências mais significativas às infâncias que acolhemos. A vida cotidiana é um reino de possibilidades, portanto, explorar para conhecer não ocorrerá em tempos predeterminados ou em currículos para um vir a ser. Obviamente, precisamos considerar que se faz necessária uma organização institucional responsável. Mas precisamos ter jornadas tão estressantes e sem sentido, seja para crianças ou para os profissionais da Educação que

\footnotetext{
${ }^{4}$ As linguagens expressivas das artes são formas de comunicação que servem para dizer o que as palavras não dizem e, portanto, não devem ser tratadas como simples entretenimento, mas como uma área do conhecimento, com conteúdos próprios, que precisam ser aprendidos para que nos tornemos sujeitos expressivos no desenho, na pintura, na construção, na modelagem, na dança, na música, nos gestos e movimentos, no faz de conta, e como qualquer aprendizado requer um tempo, um espaço e respeito ao nível intelectual e emocional de cada criança, o envolvimento com os procedimentos de observação de mundo para sustentar possível sensibilidade, elaboração e expressão (FARIA, 20I4, p. 38).
} 
acompanham as infâncias? Respondendo a este questionamento, Kuhn, Cunha e Costa (2015, p. 109) pontuam:

\begin{abstract}
Ao redor de todo o mundo há uma tendência para que as crianças busquem o conhecimento por si mesmas, livres da obsessão promovida pela correria cronológica, [...] com mais liberdade para o pensamento criativo, o que tem apontado na direção de um ensino mais agradável e prazeroso. Isso implica livrar da obrigação do sofrimento, do pânico, do esgotamento e do cansaço promovidos pela aceleração dos ritmos naturais. Outrossim, os ritmos mais suaves e a exploração do mundo da Arte têm ganhado cada vez mais espaço na educação de crianças pequenas, promovendo a expressão, a comunicação, as linguagens e, sobretudo, o diálogo que a criança necessita para inserir-se enquanto sujeito que quer e sabe como conversar com o mundo através da imaginação e da fantasia.
\end{abstract}

O conceito de artesania compreendido como processo de investigação, criação ou exploração, em que mão e mente constroem e ressignificam, não encontra espaço em planejamentos ou didáticas que carreguem consigo apenas a ideia da execução de um produto final produzido em série, da mesma forma e ao mesmo tempo - tempos predefinidos típicos dos modos de organização da produção industrial, em que se definiram o processo de produção, o ritmo de trabalho, a produtividade e o papel dos envolvidos, dentre outros fatores bem conhecidos por todos nós em estarrecedoras narrativas presentes na História do Mundo. Tais concepções permanecem influenciando os vários segmentos da sociedade mundial contemporânea. Não à toa, localizamos conceitos ou formas de organização industrial dialogando ou interferindo no campo da Educação. Palavras como gerenciamento, gerência de ensino, eficácia e eficiência, habilidades e competência, que há alguns anos pertenciam apenas ao âmbito do ensino privado, aos poucos conseguem contextualizar projetos educacionais na rede pública País afora, dentro do que se chama "gestão democrática" ou "uma educação para todos". Sem nenhuma reflexão a respeito, essas terminologias conceituais adentram os cotidianos escolares e são absorvidas pelo vocabulário dos profissionais da Educação, pelos currículos e pelas práticas pedagógicas, modificando espantosamente a compreensão quanto aos modos de ser e estar no mundo com as crianças.

Acolhemos o conceito de artesania por observarmos um próspero diálogo entre as várias áreas do conhecimento que buscam compreender as relações para além dos processos de seriação. Assim, o entendimento sobre artesania convidou-nos a pensar sobre uma harmonia entre a escola, a criança e sua família, um pensar que está para além das relações produtivas do mercado de trabalho; para além de um tempo demarcado, em que refletir sobre o que se faz é algo de menor valor.

A Educação para a Primeira Infância pede uma outra forma de pensar. É um momento em que esse estranho modo de fazer sem pensar compromete a apreciação do sensível, distanciando-se do universo das crianças, tornando impossível perceber as minúcias do processo e identificar o protagonismo infantil. Na interlocução proposta entre o conceito de artesania e o trabalho na escola, 
o docente é um artesão, ou seja, aquele que, ao fazer, pensa. Nessa relação, o conceito de tempo extrapola o previsto ou planejado, fato que autoriza o docente a dar voz e vez a outros modos de ser e estar no mundo com as crianças e suas famílias.

Pensar sobre a Educação Infantil nos dias atuais é compreender que estamos falando de um tempo e de uma especificidade da vida de crianças que adentram ambientes escolares e não escolares em que o binômio Educação e Cuidado é algo indissociável. Educar e cuidar ocorrem em ações acolhedoras organizadas por professores/as, coordenadores/as, auxiliares, merendeiros/as, dentre outros/as profissionais que reconhecem e respeitam as vivências e os saberes culturais das famílias e comunidades durante o processo de aprendizagem e desenvolvimento infantil que, neste momento, ocorre longe dos cuidados da família.

A Educação Infantil é a primeira etapa da Educação Básica e tem por finalidade o "desenvolvimento integral da criança de zero a cinco anos e II meses em seus aspectos físico, afetivo, intelectual, linguístico e social, complementando a ação da família e da comunidade" (BRASIL, LEI 9.394/I996; BRASIL CNE/CEB PARECER 20/2009). O desenvolvimento integral da criança passa pelo reconhecimento da função sociopolítica e pedagógica da $\mathrm{El}$, que deve assegurar: formação para a cidadania; redução das desigualdades sociais e da violação de direitos constitucionais; necessária compreensão de propostas pedagógicas e curriculares de qualidade que acolham as infâncias e seus cotidianos singulares, mas plurais. Essas especificidades dar-se-ão em um processo que deve respeitar a forma como as crianças, nesse "momento de suas vidas, vivenciam o mundo, constroem conhecimentos, expressam-se, interagem e manifestam desejos e curiosidades de modos bastante peculiares" (BRASIL, 2009); peculiaridades que só são percebidas enquanto outras formas de ser e estar no mundo quando a docência e a didática entrelaçam-se com a legislação da El, com conceitos e teorias que ampliam o olhar e a escuta docente e quando os saberes culturais próprios dessas infâncias e de suas famílias e comunidades passam a fazer parte da jornada de aprendizagem e dos planejamentos.

Neste sentido, o sociólogo contemporâneo Richard Sennett (2013) provoca-nos a pensar sobre a possível e necessária unidade harmoniosa entre corpo e mente. Assim, os conceitos do autor possibilitam uma discussão bem atual sobre os processos de formação de crianças e adultos, defendendo a ideia de que "fazer é pensar" e demonstrando como o trabalho com as mãos pode animar o trabalho da mente. Logo,

[...] quando estabelecemos uma separação entre a mão e a mente, a técnica e a ciência, a arte e a artesania [...], o que fica prejudicado é a parte intelectual. Isto é, dissociar o âmbito material do âmbito analítico tem como consequência uma debilidade intelectual, uma diminuição de nossa capacidade de visão e compreensão (SENNETT, 2013, p. 14). 
Se tencionarmos as proposições do autor, perceberemos que não estamos falando de algo novo. É oportuno analisar a lógica do mundo atual que, pelo conceito de tempo apressado, corrido, ansioso e/ou esvaziado de sentidos e que se desenvolve nas relações e nos diversos e distintos segmentos da sociedade globalizada, passa a equiparar o significado de produto em detrimento de processo. Compartilhando desse entendimento, Fernandes e Mignot (2008, apud KUHN; CUNHA; COSTA, 2015) discutem que o rigor no uso do tempo das práticas educativas na escola reflete uma concepção de infância e criança e de instituição escolar como um espaço que busca apenas resultados e que não parece acomodar outras temporalidades, outros ritmos, mais prolongados, respeitando o tempo que absorve. Segundo os autores, a escola limita-se à medição cronológica do tempo.

\section{Concepções da vida cotidiana e currículo}

Problematizar a vida cotidiana na intenção de promover a organização do trabalho pedagógico na Educação Infantil é entender que as minúcias do cotidiano das crianças e suas famílias dialogam com o currículo e passam a ser fios condutores das práticas docentes. É por meio das ações cotidianas que organizamos experiências capazes de reconhecer e ampliar os saberes e fazeres das infâncias e da docência.

O planejamento do percurso de aprendizagem das crianças passa a acolher os interesses infantis e garantir os direitos de aprendizagem, por meio de uma organização significativa e conceitual de tempo e espaço, disponibilizando materiais de amplo alcance, de modo a construir ambientes ricos em possibilidades e interações nesses espaços.

Compreendida a função social da Educação Infantil - educar e cuidar -, adentramos a concepção de currículo assegurada pelas Diretrizes Curriculares da área, que diz:

Art. $3^{\circ}$ - O currículo da Educação Infantil é concebido como um conjunto de práticas que buscam articular as experiências e os saberes das crianças com os conhecimentos que fazem parte do patrimônio cultural, artístico, ambiental, científico e tecnológico, de modo a promover o desenvolvimento integral de crianças de 0 a 5 anos de idade (BRASIL, 2009, p. I).

Notamos que a promoção do desenvolvimento integral da criança continua referendada na concepção de currículo para as infâncias; no entanto, são recorrentes os equívocos quanto a essa interpretação, ao observarmos a organização de práticas pedagógicas que insistem em desrespeitar as infâncias.

A Base Nacional Comum Curricular (BNCC) (2017) reitera a Educação Infantil como primeira etapa da Educação Básica, ao mesmo tempo em que traz à tona outros desafios. Embasada pela legislação que a antecede, reafirmou o comprometimento com um processo de aprendizagem e desenvolvimento das infâncias, apresentando um arranjo curricular que transgride a perspectiva 
disciplinar do Ensino Fundamental. Apresenta-nos uma relação intercampos - campos de experiências - e as minúcias poéticas cotidianas que emergem das interações, da brincadeira, dos saberes oriundos da comunidade e da cultura popular e que se expressam pelos repertórios infantis. Tal dinâmica convida-nos, diariamente, a pensar, interpretar e criar valorizando a equidade, os direitos de aprendizagem, o desenvolvimento das crianças e o nosso próprio saber-fazer pedagógico (BARBOSA, 2019). Esta observação provoca-nos a pensar sobre a organização de nosso trabalho pedagógico, bem como sua relação com as "novas" concepções de infâncias, tempos, espaços, materiais e suas materialidades, considerando os princípios éticos, políticos e estéticos que são apontados nas Diretrizes Curriculares Nacionais para a Educação Infantil (Dcnei) (BRASIL, 2009). O documento defende uma visão de mundo democrática, aberta e sensível a uma singularidade plural que deve acolher o universo dessas infâncias na reorganização de suas jornadas de aprendizagens e desenvolvimento, fato que recoloca $\circ$ papel do adulto nessa relação educativa. A escuta e $\circ$ acolhimento são metodologias de trabalho, logo, potencializam esse reconhecimento, promovendo a ampliação e a troca de saberes e fazeres culturais, inusitadas hipóteses e problematizações, consequentemente, novas teorias, novos conhecimentos pela interlocução entre crianças e crianças, crianças e adultos, adultos e adultos, ampliando repertórios não só de crianças, como também de docentes.

Se nós acreditamos que as crianças têm teorias, interpretações e questões próprias e que são coprotagonistas dos processos de construção do conhecimento, então os verbos mais importantes na prática educativa não são mais "falar", "explicar" ou "transmitir", é apenas "escutar". Escutar significa estar aberto aos outros e ao que eles têm a dizer, ouvindo as cem (e mais) linguagens com todos os nossos sentidos. Escutar é um verbo ativo, pois significa não só gravar uma mensagem, mas também interpretá-la, e essa mensagem adquire sentido no momento em que o ouvinte a recebe e a avalia (RINALDI, 20I2, p. 227-228).

A escuta potente ${ }^{5}$ identifica e acolhe sensibilidades em saberes e fazeres culturais capazes de prover um currículo para um trabalho pedagógico significativo a partir das linguagens expressivas. Ao identificarem seus saberes e fazeres culturais compondo as propostas de aprendizagem, as crianças e suas famílias passam a compreender a rede de significados e possibilidades poéticas que ali se organiza.

Ao conceber esses saberes como interlocutores de práticas pedagógicas mais significativas, percebemos a criança:

\footnotetext{
${ }^{5}$ Escuta potente? O que é isto? É a escuta que pode "dar voz, considerar, perceber, observar, favorecer autonomia" [...], é o que se "convencionou chamar de escuta infantil". Todos estes verbos juntos reconhecem [...] "a criança como indivíduo pleno, capaz e dotado de subjetividades que fazem dela um legítimo ator social [...]" (FRIEDMANN, 2019; 2020). Neste texto, a escuta passou a ser um potente instrumento docente para legitimar vozes de crianças e de adultos no chão da escola pública na Educação Infantil, fato que nos trouxe significativas provocações e possibilidades à docência com crianças.
} 
[...] centro do planejamento curricular, é sujeito histórico e de direitos que se desenvolve nas interações, relações e práticas cotidianas a ela disponibilizadas e por ela estabelecidas com adultos e crianças de diferentes idades nos grupos e contextos culturais nos quais se insere. Nessas condições ela faz amizades, brinca com água ou terra, faz-de-conta, deseja, aprende, observa, conversa, experimenta, questiona, constrói sentidos sobre o mundo e suas identidades pessoal e coletiva, produzindo cultura (BRASIL, 20/2009).

Considerando que, na Educação Infantil, tudo é pedagógico, o cotidiano dessas infâncias carregadas de valores e significados muito particulares prevê a consolidação dos princípios fundamentais presentes na DCNEI n 05 (BRASIL, 2009) como de extrema relevância para o processo de aprendizagem e desenvolvimento infantil. Para tal, a BNCC/2017 vem apresentar seis direitos de aprendizagem: Conviver, Brincar, Explorar, Participar, Expressar e Conhecer-se, para explicar-nos os modos como as crianças aprendem. "A criança aprende para poder problematizar o mundo" (FOCHI, 2020) ao interrogar, descobrir ou investigar outros modos e tempos de viver. "Direitos de aprendizagem são um horizonte para pensar o processo da criança” (idem, ibidem).

$\mathrm{Na}$ perspectiva de horizonte, o conceito de artesania agrega valor à discussão novamente, quando se compreende que os direitos de aprendizagem emergem das interações e da brincadeira e, da mesma forma, conversam com a organização do trabalho pedagógico na escola. No entanto, compreendemos também que, se não estamos abertos ao imprevisível ou ao inusitado - que, provavelmente, solicitará outros modos de fazer e de pensar sobre os modos e tempos como as crianças aprendem -, não promoveremos aprendizagens significativas.

Assim, outros modos e tempos de fazer e de pensar devem compor as proposições docentes. Visto que a observação e o registro das interações e da brincadeira infantil são parâmetros para uma avaliação consciente de todo este processo, logo exigirão outros modos de analisar o planejamento da jornada de aprendizagem dessas infâncias e, consequentemente, outro tipo de organização que possa prever o acolhimento da compreensão de que "fazer é pensar", ou seja, outros modos e tempos indissociáveis e incompatíveis com a concepção de tempo presente em um currículo predeterminado. Sendo assim, neste tipo de planejamento, o docente será o artesão que se realiza ao não esgotar as possibilidades, fato que o instigará a buscar novos modos de ser docente, na intencionalidade de provocar e potencializar o fazer e o pensar com as crianças e suas famílias e, assim, construir e reconstruir hipóteses, ampliando teorias, com vistas a significar o fio condutor dos planejamentos docentes.

Entre possibilidades e inúmeros desafios, encontramos os profissionais da Educação precisando autorizar-se a rever urgentemente sua formação acadêmica, seja no âmbito inicial ou continuado. Convidar as instâncias competentes a conhecer e reconhecer a potência dos "novos saberes" presentes nas relações e nas descobertas cotidianas no chão da escola passa a ser um ato político, que 
pretende dar voz aos autores deste processo, identificando-os a partir de suas histórias e percursos. Redescobrir com as crianças e as famílias o prazer de estar e observar os grupos infantis durante as interações e a brincadeira e, de forma "bem" particular, considerar a singularidade de cada criança quando faz e pensa o planejamento (FORMOSINHO; FORMOSINHO, 20I7).

Diante do cenário apresentado, estamos nós, docentes dessas infâncias, buscando uma pedagogia harmônica, holística e ecológica, entre crianças e adultos, em que o processo de aprendizagem e desenvolvimento infantil dê-se pelo reconhecimento do corpo enquanto potencializador de possibilidades pedagógicas mais significativas e que ultrapassam uma organização de saberes predefinidos em um tempo previsto para uma criança, que é um vir a ser.

\section{Linguagens expressivas: contribuições à docência}

Quando falamos de linguagem, referimo-nos aos diversos modos que as crianças (os seres humanos) representam, comunicam e expressam o seu pensamento com diversos meios e sistemas simbólicos; as linguagens, portanto, são as múltiplas fontes ou gêneses do conhecimento. As linguagens poéticas são formas de expressão fortemente caracterizadas por aspectos expressivos ou estéticos, como a música, o canto, a dança, ou a fotografia (DAHLBERG; MOSS IN VECCHI, 20I7, p. I3).

Partilhamos das ideias dos autores ao explicar que a palavra linguagem, neste texto, é utilizada no sentido de compartilhar sentidos e comunicar significados; ler as entrelinhas, interpretar, expressar e produzir significados simbólicos e no sentido de movimentos que se realizam por meio de práticas, saberes e fazeres que as crianças já possuem. Neste ponto do texto, apresentamos uma experiência construída a partir dos interesses, saberes e fazeres culturais das crianças do $I^{\circ}$ Período $C$ (4 anos) junto às memórias afetivas e poéticas de seus avós acerca de suas infâncias, seus brinquedos e brincadeiras. As narrativas passaram a compor a proposta no sentido de conhecer para aprender juntos. O acolhimento passou a ser um método de trabalho (STACCIOLLI, 2013), em toda a sua complexidade e seu significado. Acolher requer compreender que aprendemos em companhia (OLIVEIRA; FORMOSINHO, 2017). Para tal, estarmos prontos para receber o que vem de outrem é necessário ao reconhecimento de outros modos de ser e estar no mundo, "no sentido de estar aberto à possibilidade de fazer coisas de maneira diferente, para o deslocamento de uma esfera de hábitos para outra" (SENNETT, 2020, p. 3II-3/2). Nesse deslocamento, o adulto mediador do processo de aprendizagem e desenvolvimento infantil que acompanha as crianças assume um outro papel: acolhe os interesses da criança; reconhece-a sujeito e protagonista de sua formação, valoriza os saberes e fazeres culturais de suas famílias e comunidades, entendendo-os fios condutores e reveladores de práticas cotidianas e outras possibilidades pedagógicas. Possibilidades sensíveis, poéticas e significativas, para além dos saberes e fazeres que os docentes carregam consigo e que já fazem parte de sua história de vida e trajetória profissional. 
Assim, o Projeto Brinquedos e Brincadeiras do Tempo dos Avós surgiu no sentido de superarmos, mesmo que de forma parcial, uma preocupação crescente entre a escola e as famílias quanto aos altos índices de violência presentes nas ruas e comunidades dos arredores da escola e que vêm privando as crianças das brincadeiras próprias de suas infâncias. Tal situação expõe as crianças a longas horas contidas em suas residências e em frente às telas. Por meio da natureza investigativa própria dessa idade, as crianças desenvolvem habilidades específicas na utilização de recursos tecnológicos, facilitando o acesso a sites que nem sempre são indicados aos seus grupos etários. Com bastante frequência, determinados espaços de informação apresentam modos estereotipados de ser e estar no mundo que não contribuem com a formação das crianças. Apesar de muito inteligentes, em situações como estas, as crianças necessitam da mediação de um adulto, ampliando suas possibilidades para fazer boas escolhas.

O Centro Municipal de Educação Infantil Hermé Miranda localiza-se no Tabuleiro do Martins, na periferia de Maceió, no Estado de Alagoas, em um bairro que possui comércios formais de pequeno e médio portes, escolas, posto de saúde e outros serviços básicos. A predominância do setor informal é forte, aliás, constitui a fonte econômica de subsistência de muitas famílias. Nessa região, há poucos espaços de lazer, com uma estrutura mínima que atende às necessidades infantis. O saneamento básico na comunidade é muito precário e as raríssimas praças existentes no bairro acabam transformando-se em grandes depósitos de lixo que oferecem riscos à saúde das crianças e da população em geral.

O brincar é compreendido em sua inteireza e relevância no processo infantil. Contudo, diante do cenário de violência que acomete as famílias atualmente, as crianças acabam sendo privadas de brincar em ruas, calçadas, praças e parques. Cada vez menores, suas moradias promovem experiências brincantes circunscritas que inibem o imaginário infantil - mesmo que seja de nosso conhecimento que, em suas invencionices, as crianças assumem papéis diversos e são capazes de transformar uma pequena caixa de papelão em um navio em alto-mar, produzindo incríveis enredos. São crianças que, na maioria das vezes, são assistidas por seus avós em famílias com estruturas e realidades diversas dentro de um contexto de grande vulnerabilidade social.

Desse modo, buscando assegurar o desenvolvimento integral da criança (BRASIL, 1996; BRASIL, 2009), considerando nossa frágil estrutura espacial, mas atentas a um trabalho significativo e de qualidade, procuramos escutar com todos os sentidos, para conhecer, propor e resgatar a percepção do brincar. $O$ projeto foi planejado e desenvolvido de forma colaborativa com a equipe pedagógica da escola. As interações e a brincadeira compreendidas como eixos centrais do trabalho pedagógico com as crianças precisavam dialogar com os seis direitos de aprendizagem que, norteados pelos princípios éticos, políticos e estéticos, devem fazer parte dos projetos escolares. Assim, a proposta pedagógica da escola é sustentada por relações, interações e práticas educativas que 
respeitem as experiências da vida cotidiana e cultural das crianças, de suas famílias e comunidades, buscando:

A valorização da diversidade das culturas das diferentes crianças e de suas famílias, por meio de brinquedos, imagens e narrativas que promovam a construção por elas de uma relação positiva com seus grupos de pertencimento, deve orientar as práticas criadas na Educação Infantil, ampliando o olhar das crianças desde cedo para a contribuição de diferentes povos e culturas (BRASIL, PARECER CNE/CEB 20/2009).

O projeto promoveu o resgate de brinquedos e brincadeiras do tempo dos avós, contribuindo para refletir sobre a importância dos vínculos afetivos entre as crianças, as famílias e a escola. Nesta dinâmica, as heranças culturais passaram a fazer parte do nosso cotidiano de forma significativa e consistente. As linguagens da Arte ampliaram o repertório das crianças e aproximaram as famílias (em seus núcleos familiares, filhos, netos e avós) pelas memórias afetivas. As experiências brincantes dos avós encantaram nossas tardes. O compartilhar de brincadeiras conhecidas, desconhecidas ou modificadas pelo tempo trouxe estranhamentos, "encantamentos, maravilhamentos, ingredientes essenciais para a recriação do cotidiano pessoal e profissional, rompendo com a forma, ousando outros desenhos para o dia a dia" (LEITE; OSTETTO, 2004, p. 12). O reconhecimento de outros saberes identificados nos relatos dos avós problematizou nossa organização docente, uma vez que a participação das famílias exigiu o desprendimento dos planejamentos previamente elaborados em horários e espaços fixos originários de um currículo prescrito. Cada docente, com seu respectivo grupo etário, procurou aprimorar o olhar e a escuta para acolher interesses, desejos, curiosidades das crianças e anseios das famílias. Para a turma do $1^{\circ}$ Período $C$, processos de investigação sempre promoveram longas situações reais de aprendizagem. O fazer e o pensar acerca do processo e das possibilidades existentes em cada experiência proposta exigiram a organização de um planejamento que não fosse uma "fôrma", de modo que tornasse possível "repensar, revisitando, buscando novos significados para a sua prática pedagógica" (OSTETTO, 2004, p. 177).

Com liberdade, as crianças expressavam-se, movidas por uma curiosidade vigorosa, por meio das linguagens expressivas: desenho, pintura, modelagem, literatura, música, fotografia, dentre outras maneiras, evidenciando uma organização estruturante dos modos de ação sobre os materiais disponíveis na proposta do projeto. Em suas estratégias de investigação, todos os sentidos foram acionados a partir das descobertas decorrentes das materialidades dos elementos manipulados nas práticas artísticas. Suas hipóteses e escolhas construíram percursos que nos convidavam e nos desafiavam, inspirando outros desafios pedagógicos. No entanto, ao mesmo tempo, apontavam para um vácuo enorme na nossa formação acadêmica inicial e continuada, ora aproximando-se, ora distanciando-se do diálogo e do conflito entre o currículo que norteia a organização do trabalho pedagógico "para" crianças e os inusitados saberes e fazeres culturais infantis que se construíam 
diariamente. Dessa forma, nossa organização docente entrou no conflito entre atender à burocracia necessária da instituição e/ou acolher outros modos de conceber o mundo pelos olhos infantis.

A construção do conhecimento é um processo de grupo. $O$ indivíduo se alimenta das hipóteses e teorias de outros indivíduos e dos conflitos com os outros, e avança com a coconstrução de partes do conhecimento com os outros, através de um processo de confirmação e divergência. Acima de tudo, conflitos e distúrbios nos forçam a rever constantemente nossos modelos interpretativos e teorias sobre a realidade, e isso se aplica tanto para as crianças quanto para os adultos (RINALDI, 2012, p. 237).

O conflito gerado pela possibilidade de acolher o inusitado exigiu de nós um reposicionamento. Acolher o novo levou-nos a outra escuta. Uma escuta com todos os nossos sentidos que exigiu de nós estudo, investigação e experimentação. Houve a urgência de desacomodar para ousar, e então nos autorizar. Retomaríamos, ali, o sentido de artesania e passaríamos a fazer e pensar, mas, desta vez, fazer e pensar juntos, com as crianças e suas famílias, com os conceitos e as teorias. Observamos que o conflito, para o adulto, é algo difícil de lidar. Para as crianças, o sentido de conflito leva à investigação e corresponde a uma força vital, pois elas estão sempre abertas ao desconhecido, sentem-se provocadas e nunca satisfeitas.

Nesta perspectiva de estranhamento, de inexperiência e até mesmo de incompetência pedagógica, reconhecendo a riqueza existente nas linguagens da Arte, para nós, em grande maioria, pedagogos de formação inicial, que quase nada experimentamos deste universo das Artes, ter que construir caminhos caminhando é um ato de ousadia. Assim, o barro chegou a nós pelo relato da infância de uma avó que, na simplicidade cotidiana de seu viver, trouxe toda uma potência de exploração e investigação que ganhou unanimidade pela turma.

O barro promoveu ricas experiências estéticas em seus tons, sua maleabilidade, seus cheiros quando seco ou molhado, suas texturas. Ele foi apresentado às crianças, primeiramente in natura, e só mais tarde a argila industrializada acresceu outras experiências. As crianças experimentaram a matéria no corpo. Brincaram de se pintar e de se melecar. Produziram tinta de barro em várias tonalidades e texturas. Pintaram com pincéis industrializados, pincéis de folhas secas com cabinhos de gravetos, buchinhas de espuma ou fibra natural e outros equipamentos. Os dedos gotejaram o papelão que serviu de base para o chão, as paredes e $\circ$ telhado da casa da fazendinha que construíram. Igualmente, gotejaram os cartazes que traziam citações de autores que enriqueciam a proposta, como, por exemplo, Gandhy Piorsky. As crianças também organizaram quadros e esculturas, fizeram comidinhas com barro, bolinhos de carne e sopa com capim e ouviram as histórias de seus avós sobre os brinquedos e as brincadeiras de suas infâncias com o barro e a vida na roça. A cada narrativa, outras possibilidades surgiam e o encantamento potencializava as criações. 
Aos poucos, as crianças foram percebendo que não havia apenas um único modo de conhecer histórias, pois, além das narrativas escritas convencionalmente, elas também eram feitas por pessoas comuns, como seus avós. Por mais que as crianças experimentassem problematizações diversas acerca da potência dos livros presentes no espaço da escola, as narrativas das infâncias de seus avós aguçavam sua imaginação. As mimeses da vida social estavam sendo apresentadas pelas narrativas dos avós e seriam:

As brincadeiras de casinha e as de cabana, de fazendinha ou de animais construídos, de boneca, de carroça, de carrinho, incluindo os carros de boi de madeira, de vara e de lata, de miniaturas, os brinquedos de modelar, as representações de casamento, nascimento, trabalho e beleza, os rituais de morte e os festejos religiosos, brinquedos e brincadeiras das entranhas de animais e plantas feitos de ossos e seivas... (PIORSKY, 2016, p. 20).

Uma memória poética organizada em relatos ricos e únicos que só quem experimentou a inteireza do brincar poderia contar. A maioria das famílias viveram suas infâncias em cidadezinhas ou povoados do interior de Alagoas e assim experimentaram uma outra forma de viver o brincar e o mundo. Muitos daqueles avós trabalhavam com suas famílias na roça. Um trabalho cansativo para uma criança, mas que, pelas narrativas dos avós, era possível perceber que a poética da infância permanecia lá, guardada em memórias de um período que ficou muito distante e que agora era resgatado prazerosamente, dada a importância devida, encantando os ouvidos atentos das crianças e dos adultos.

Como explicita Sennett (20I3), o trabalho artesanal exige encontro, diálogo, tempo. O artífice, em seu trabalho, não precisa ter controle absoluto sobre "[...] o que vem pela frente ao começar [uma ação]" (SENNETT, 20I3, p. 29I). Dessa maneira, não se fecha prematuramente um ciclo de trabalho. No trabalho com as crianças pequenas, também não podemos saber de antemão o percurso a ser percorrido ou onde ele chegará, ou quais aprendizagens serão construídas: podemos ter uma direção e um planejamento que vai se transformando ao longo do caminho. Para isso, é necessário que, no trabalho do professor, haja lugar para a metamorfose, para o não apagamento das marcas do que foi vivido, daquilo que se experencia na vida cotidiana - enfim, espaço para a valorização da história que se constrói na relação com as crianças (GOBBATO; BARBOSA, 2019, p. 9).

Durante cinco meses, outros modos de ser e estar no mundo foram-nos apresentados e passaram a compor a organização da jornada de aprendizagem das crianças, bem como foram lançados inúmeros desafios à nossa docência. Recorremos, várias vezes, a estudiosos, tanto no âmbito da formação docente e das linguagens da Arte, quanto relacionados ao processo de aprendizagem e desenvolvimento infantil e a outros sentidos para o fazer e o pensar, no intuito de não permitir o apagamento das marcas do que foi vivido.

Não subverter a ordem estabelecida que prescreve currículos sem sentido em atendimento à burocracia das instituições com uma organização de tempo que não permite entender que fazer é 
pensar não encontra mais espaço em experiências estéticas significativas; no entanto, precisamos acolher o entendimento de que "para encantar, é preciso encantar-se" (OSTETTO, 20I0).

A valorização da escuta exigia uma outra compreensão: a de que "o pensamento e o sentimento estão contidos no processo do fazer" (SENNETT, 2020, p. 17). Logo, a reflexão acerca do "fazer e do pensar" necessitaria ser ressignificada, uma vez que, pelas linguagens expressivas, estávamos construindo redes de significados e possibilidades poéticas à docência e ao processo de aprendizagem e desenvolvimento infantil. Não existiam mais respostas ou certezas, e sim perguntas que buscavam e provocavam outras perguntas inteligentes, relançando contextos a partir das pistas e dos indícios deixados pelas próprias crianças e por suas famílias, na tentativa de compreender o significado verdadeiro da investigação.

A sensibilidade docente passou a ser um forte instrumento de avaliação, pois considerou como ponto inicial dessa reflexão as ações pedagógicas que se seguiram, buscando alcançar novos significados e, assim, ser possível ultrapassar o planejado ou o previsível. A partir dessa compreensão, o autor Severino Antônio (2013, p. 16) diz-nos que a arte da escuta ou a escuta poética "exige práticas e exercícios diários para se reconhecer, dentre os emaranhados de sons, os timbres mais vívidos e singulares que vivem dentro de uma criança". O espaço escolar entendido como espaço de criatividade e de produção cultural ajudou-nos a ampliar a reflexão sobre a dinâmica de pensar a ação educativa e os processos que fecundam a realização de uma proposta pedagógica de qualidade e significados.

\section{Possibilidades poéticas do projeto com as crianças}

A palavra "projeto" evoca a ideia de processo dinâmico, de itinerário. Ela é sensível aos ritmos da comunicação e incorpora a significância e o timing da pesquisa e da investigação das crianças. A duração de um projeto, assim, pode ser curta, média ou longa, contínua ou descontínua, com pausas, suspensões e recomeços (RINALDI, 2012, p. 239).

As histórias infantis, em suas narrativas ficcionais ou não ficcionais, também dialogaram com os momentos de construção de novos conhecimentos. O envio de livros para casa pela Sacolinha Viajante 6 oportunizou que as famílias se aproximassem ainda mais da escola. Mesmo aquelas famílias que não sabiam ler valorizaram o tempo que as crianças dedicavam à leitura. Muitas vezes, elas relatavam que liam para seus pais. Ao retornar para a escola, o espaço para a contação da história era escolhido e organizado pelas crianças. Providenciávamos tapetes, almofadas e cadeirinhas que eram distribuídos em círculo, ou não. Empoderadas, elas transformavam o ambiente, tornando-o diferente a cada nova história. $\mathrm{O}$ importante mesmo era fazer conhecida a forma como o livro foi acolhido pelas famílias.

\footnotetext{
${ }^{6}$ Sacolinha Viajante foi o nome recebido pelo projeto do CMEI que enviava, semanalmente, livros para as casas das crianças e tinha como objetivos ampliar o repertório e o prazer da leitura.
} 
Entre idas e vindas com os livros, tivemos uma grata surpresa. A obra Diálogo ou A vaca que não foi pro brejo, de Mônica Versiani Machado, trouxe uma narrativa e uma ilustração bastante incomuns. O diálogo dá-se entre um boi e uma vaca. A sinopse revela: boizinhos e vaquinhas danados de feios. Ou será que são danados de bonitos? Feios ou bonitos, é tudo bem divertido, dos bichos ao diálogo. O livro provocou euforia nas crianças, pelas ilustrações diferenciadas. Foi bem acolhido pelas famílias e, particularmente, pelos avós, que passaram a nos contar como foram suas infâncias, descrever alguns de seus brinquedos e como, geralmente, eram produzidos. Seu reconto não se deu da mesma forma que os outros, uma vez que a Sacolinha Viajante, até então, levava, a cada semana, livros diferentes e escolhidos pelas próprias crianças para suas casas. No entanto, este livro, em particular, passou a visitar muitas casas nos finais de semana e, à medida que retornava, inusitados relatos de outras infâncias chegavam pelas vozes das crianças e pelas vozes de alguns avós que, timidamente, aproximavam-se de nós para comentar suas aventuras infantis.

As memórias das infâncias continuavam a nos surpreender. Como a maioria das famílias procediam de cidades interioranas do Estado de Alagoas e a roça fazia parte de suas vivências infantis, construir brinquedos a partir das plantações de suas propriedades familiares era algo natural às crianças. Naquela época, ter acesso a brinquedos industrializados era quase impossível. Alguns relatavam que, no máximo, tinham carrinhos feitos de lata ou pedacinhos de troncos de árvores, que se movimentavam puxados por cordões. As bonecas ou bruxinhas de pano ou sabugo de milho povoavam o imaginário daquelas infâncias. Existem feiras livres nos interiores alagoanos em que ainda encontramos esses brinquedos artesanais.

Os avós relatavam que a brincadeira se estabelecia em meio ao trabalho de ajudar seus familiares. À medida que os tubérculos eram selecionados para o consumo ou a venda, aqueles que não atendiam à demanda eram descartados para servir de alimento aos animais ou à produção artística das crianças. A esses vegetais descartados juntavam-se gravetos, folhas secas, flores de coco, sementes de formatos e cores diversas, pedrinhas, sabugos de milho e outros materiais da natureza que complementavam a construção dos animaizinhos que ilustravam seus enredos brincantes.

Obviamente, esses avós não percebiam questões pedagógicas implícitas em suas experiências infantis e, quando convidados por nós a falar um pouco mais sobre os relatos que chegavam pelas vozes de seus netos, sentiam-se constrangidos, mas, ao mesmo tempo, percebiam-se acolhidos, pois, por meio da escuta atenta e sensível, criamos contextos diversos com as crianças. E, assim, ao disponibilizar materiais da natureza para as crianças, um horizonte de possibilidades continuava a se abrir pelas materialidades ali exploráveis. As crianças produziram cavalos, bois, cabras, bonecas, casinhas e outros objetos. Os relatos apresentaram diversas possibilidades de brinquedos. Isso nos levou a outras pesquisas sobre propostas com materiais da natureza. 
O problema do desperdício também foi alvo de nossas conversas e permitiu revermos aspectos relacionados a um processo integral (holístico e ecológico), envolvendo também questões culturais das famílias presentes nas narrativas dos avós, como, por exemplo, questionamentos em relação à forma como as crianças de hoje relacionam-se com o alimento e a rejeição que têm ao experimentar aquilo que não conhecem.

Durante o processo, recolhemos, na feira, alguns tubérculos que também eram descartados. As crianças encontraram o tal do melãozinho-bravo descrito por um avô e reconhecido por uma criança pertencente a outro grupo etário e que, diariamente, observava nossas experiências de forma muito curiosa. Ela ainda nos informou que aquele melãozinho servia de comida para as cobras. $\bigcirc$ "danado" do melãozinho, assim denominado pelo avô de uma de nossas crianças, é também conhecido por melão-de-são-caetano, uma planta medicinal.

As partilhas continuavam, inclusive recebemos tomatinhos em rama de uma família. Pelo relato do avô que doou o fruto, esse tomatinho é o nosso tomate-cereja, hoje disponível nos supermercados e considerado caro por muitos de nós. Entretanto, na infância deste senhor, o vegetal era comum na roça e reproduzia-se em grande quantidade, sem despertar interesse daqueles que cultivavam a terra.

No nosso Espaço da Arte, havia pias e torneiras para a utilização de água e uma grande mesa com cadeiras que permitiam que as crianças trabalhassem juntas, facilitando as interações entre elas. Nesse sentido, a organização desta prática foi planejada, detalhadamente, na intenção de proporcionar uma estrutura que favorecesse $\circ$ acesso aos materiais e a problematização de hipóteses, potencializando suas construções. Procuramos criar um ambiente convidativo e gerador de curiosidade e encantamento, ingredientes essenciais no trabalho com as linguagens expressivas.

Adentrando o mundo das infâncias dos avós por meio de suas narrativas, inúmeras possibilidades de organização de contextos de aprendizagem surgiram. De um modo singular, as contribuições alcançadas pelas partilhas entre os avós, as crianças e nós, profissionais da Educação Infantil, legitimavam outros saberes e fazeres. Demais conceitos trazidos por pesquisadores de áreas afins contribuíram para "desestabilizar o estabelecido, desacomodar, esgarçar o tecido necrosado pela mesmice e abrir novos canais, sempre mais e mais" (LEITE; OSTETTO, 20 I2, p. 15), proporcionando, assim, um pensar prazeroso, rico em possibilidades, que nos torna artífices da ação pedagógica, da compreensão de fazer junto, fazer com e perceber que "[...] para aprender com as coisas, precisamos saber apreciar [...]" (SENNETT, 2020, p. 18).

O repensar acerca da concepção de didática trouxe grande contribuição à ação investigativa na escola. Desse modo, ajudou a pensar a pesquisa como o entrelaçamento de muitos fios, sustentada pela escuta, pelos registros escritos e fotográficos que compõem a documentação pedagógica, promovendo a autoavaliação docente e a interpretação de uma relação recursiva das experiências 
vividas com a participação das famílias. Possibilitou também refletir sobre outros modos de ser e estar no mundo com as crianças de maneira respeitosa e solidária, valorizando os saberes e fazeres culturais das crianças, de suas famílias e da comunidade, reconhecendo que estes saberes e fazeres devem compor os currículos escolares, os planejamentos dos profissionais da Educação e a jornada de aprendizagem das crianças. Não ter respostas não é ruim! A dúvida, a incerteza e o erro como recurso são capazes de modificar contextos. Não ter perguntas é a questão central!

$\mathrm{Na}$ Educação Infantil, a criança é o centro do planejamento curricular e sujeito de seu processo de aprendizagem e desenvolvimento. Seu protagonismo é valorizado nas experiências que lhes são oportunizadas por meio de inúmeras linguagens que perpassam todo o processo. $O$ olhar e a escuta são instrumentos que compõem a documentação pedagógica no intuito de aproximar os registros (escritos, orais, fotográficos, etc.) do ressignificar de práticas e saberes mais significativos. O projeto protagonizou a Mostra de Arte do CMEl pelas vivências culturais das famílias quando acolheu suas narrativas e seus modos de ser e estar no mundo.

As experiências pensadas para ampliar as vivências infantis promoveram um ressignificar acerca dos materiais que disponibilizamos para as crianças e que alcançaram excelentes perspectivas criativas e inusitadas. A possibilidade de construção e reconstrução de novos espaços, tempos, interações e o sentido da brincadeira para o planejamento e a jornada de aprendizagem das crianças respeitou, antes de mais nada, seus interesses, questionamentos e a forma como reagiram diante das propostas que Ihes foram apresentadas. Claramente, foi possivel perceber que as crianças têm saberes diferentes daqueles que os adultos possuem, porque não são limitadas por preconceitos e acolhem com naturalidade e respeito outros pontos de vista, por meio de novas perspectivas e possibilidades de brincar.

\section{Considerações finais}

Este texto propôs-se a refletir sobre uma experiência que envolveu as linguagens da Arte entre crianças pequenas (4 anos) na Educação Infantil da rede pública alagoana. A proposta considerou experiências brincantes e culturais dos avós das crianças, narradas por eles e por seus netos, alunos do CMEI, que tornaram nossas tardes surpreendentes. Estes saberes e fazeres culturais e singulares enriqueceram repertórios de crianças e adultos e promoveram um novo olhar e possibilidades outras à docência e à didática. Um pensar prazeroso que proporcionou a todos fazer e pensar juntos, fato que tornou o projeto Brinquedos e Brincadeiras do Tempo dos Avós um processo extremamente rico e significativo.

A Educação Infantil apresenta-nos um arranjo curricular numa relação intercampos - campos de experiências - em que se deslocam do centro do currículo as áreas do conhecimento acadêmico 
para as práticas cotidianas sociais e culturais. São saberes e fazeres culturais formativos presentes na vida das crianças e de suas famílias que ainda permanecem fora das propostas e dos planejamentos pedagógicos das escolas. A relação intercampos vem provocar para promover outros diálogos e as linguagens expressivas têm se mostrado ricas em possibilidades.

Buscamos apoio em conceitos de várias pedagogias, como a pedagogia do cotidiano, da/na participação, da escuta, da infância, dentre outras, no intuito de acolher as crianças, suas infâncias e seus modos surpreendentes de ser, habitar, escutar e relacionar-se no/com o mundo. No entanto, a forma como concebemos os saberes e fazeres culturais das crianças e os assumimos como dimensões formativas necessárias à superação dos deficits de nossa formação acadêmica inicial ou continuada poderá inviabilizar, ou não, qualquer uma das conceitualizações apresentadas.

O conceito de artesania compreendido como processo de investigação, criação ou exploração, em que mão e mente constroem e ressignificam o mundo, não encontra espaço em planejamentos ou práticas que não considerem outros modos de ser e estar com crianças. A criança, esta criatura por excelência tátil, tem olhos nas mãos. Quase só sabe ver com as mãos; ver com os olhos não lhe basta, pois o campo de repercussões por ela almejado é das mais recuadas impressões corpóreas [...] (PIORSKY, 2016, p. 109).

Pelas linguagens expressivas, interações, brincadeiras e narrativas, conhecemos outros modos de a infância ser e estar no mundo. Acolhemos saberes inusitados e potentes que causaram estranhamento, mas possibilitaram um desacomodar ao convidar os profissionais da Educação a olhares mais sensíveis e profundos. Afinal, não estamos acostumados a considerar o imprevisível ou ousar e potencializar o improvisado que está para além dos nossos planejamentos, muitas vezes inflexíveis, principalmente quando o sujeito que promove o conflito e desestabiliza nossa organização são crianças em suas infâncias.

$O$ ato de acolher passa a ser uma metodologia de trabalho investigativo para descobrir quais hipóteses e teorias são produzidas com as crianças e as famílias sobre as brincadeiras e os brinquedos dos tempos dos avós. Assim, suas narrativas, saberes, fazeres, valores cotidianos e culturais possibilitaram-nos conhecer outros modos de ser e estar de profissionais da Educação Infantil, bem como estudos aprofundados acerca da riqueza e da potência da simplicidade complexa das relações cotidianas, dos materiais e de suas materialidades, etc. (HOLM, 20I7; PIORSKY, 20I6).

Sendo assim, os fascinantes saberes, fazeres e valores culturais presentes nas práticas docentes e organizados em função de um currículo que se constrói diariamente, após uma escuta atenta, não deveriam ser banalizados. Ao contrário, os estranhamentos convidam-nos ao encantamento, provocando-nos o maravilhamento que torna o complexo tão simples e tão relevante em nossas vidas. Um currículo que se organiza no diálogo entre crianças, famílias e docentes apresenta 
como característica específica não se configurar apenas nos documentos, nos discursos elaborados [...], mas se manifestar, de modo prioritário, em todas as interações do dia a dia (BARBOSA, 2009).

Propor uma autoavaliação acerca da docência e da didática na Educação Infantil é um grande desafio: convida a todos, de forma consciente e responsável, a subverter a lógica de planejamentos rígidos que não compartilham do imprevisível ou improvisado significativo, sequer de uma outra ideia de tempo ou construção coletiva. Consideramos que o imprevisível ou o improvisado a que nos referimos requer reflexão e confronto, uma vez que a mediação do adulto-criança possibilitará ampliar, se necessário, ou acolher os saberes, fazeres, valores ou outros modos de ver o mundo. De modo algum desejamos reforçar concepções que desconstroem a relevância do papel do/da docente no processo infantil ou uma concepção de "escuta" que neutraliza o papel de mediador do profissional da Educação que acompanha as interações e a brincadeira da criança. Tal entendimento é completamente equivocado, desmerece e desvaloriza o trabalho de inúmeros profissionais da Educação Infantil que ainda se maravilham com a riqueza dos saberes, fazeres e valores culturais construídos pelas crianças e por suas famílias. Deste modo, questionamo-nos: afinal, qual seria a função do/da professor/a na Educação Infantil em um contexto equivocado como este?

A rigidez do tempo predeterminado que direciona ações apenas burocráticas no espaço escolar torna impossível experimentar, investigar, conhecer e reconhecer, na cultura de nossas infâncias, outros saberes, fazeres, valores, modos, materiais e tempos que transcendem um currículo previsto e um deficit considerável na formação do profissional da Educação.

A forma como acolhemos e respeitamos a criatividade e a imaginação infantis deve potencializar outros modos e tempos de fazer e de pensar. Logo, serão exigidos outros questionamentos problematizadores, a partir da observação e dos registros das interações e da brincadeira das crianças, tomados como parâmetros norteadores de um trabalho que valoriza os percursos da infância.

\section{Referências}

ANTÔNIO, S. Uma pedagogia poética para as crianças. Americana, SP: Editora Adonis, 2013.

BARBOSA, M. C. S. Práticas cotidianas na Educação Infantil: bases para a reflexão sobre as orientações curriculares. Ministério da Educação, Brasília, 2009. Disponível em: http://portal.mec.gov.br/dmdocuments/relat_seb_praticas_cotidianas.pdf. Acesso em: 28 abr. 2020.

BARBOSA, M. C. S. A BNCC e os direitos das crianças: Educação Infantil em evidência. uma entrevista de Maria Carmen Silveira Barbosa para a RCC. [Entrevista cedida a]. Revista Com Censo: Estudos Educacionais do Distrito Federal, [S.I.], v. 5, n. 2, p. 9-13, abr. 20I8. Disponível em: http://www.periodicos.se.df.gov.br/index.php/comcenso/article/view/452/27l. Acesso em: $22 \mathrm{dez}$. 2019. 
BRASIL. Ministério da Educação. Resolução CNE/CEB n 5, de 17 de dezembro de 2009. Fixa as Diretrizes Curriculares Nacionais para a Educação Infantil. Disponível em: http://portal.mec.gov.br/index.php?option=com_docman\&view=download\&alias=2298-rceb00509\&category_slug=dezembro-2009-pdf\&Itemid=30192. Acesso em: 20 abr. 2020.

BRASIL. Ministério da Educação. Parecer CNE/CEB 20/2009, de II de novembro de 2009. Revisão das Diretrizes Curriculares Nacionais para a Educação Infantil. Disponível em: http://portal.mec.gov.br/index.php?option=com_content\&id=12745\&ltemid=866. Acesso em: $20 \mathrm{abr}$. 2020.

BRASIL. Ministério da Educação. Base Nacional Comum Curricular (BNCC). A Educação Infantil na Base Nacional Comum Curricular. Disponivel em: http://basenacionalcomum.mec.gov.br/abase/\#infantil. Acesso em: 20 fev. 2020.

BRASIL. Ministério da Educação. Lei $\mathbf{n}^{\circ} \mathbf{9}$ 9.394/96, de 20 de dezembro de 1996. Institui a Lei de Diretrizes e Bases da Educação Nacional (LDB). Disponível em: http://www.planalto.gov.br/ccivil_03/leis/19394.htm. Acesso em: 0I jun. 2020.

FARIA, A. C. Linguagens expressivas e a formação de professores para a Educação Infantil: um estudo de projeto pedagógico. 2014. Dissertação (Mestrado em Educação Escolar) - Faculdade de Ciências e Letras (Campus Araraquara), Universidade Estadual Paulista "Júlio de Mesquita Filho", Araraquara, 2014. Disponível em: https://repositorio.unesp.br/bitstream/handle/I I 449// I5564/000809822.pdf;jsessionid=8DAECI 7FB8 4B342EC28I AE729F5 I 38AF?sequence=I. Acesso em: 12 dez. 2020.

OLIVEIRA-FORMOSINHO, J. Pedagogia-em-Participação: a documentação pedagógica no âmago da instituição dos direitos da criança no cotidiano. Revista Em Aberto, v. 30, n. I00. Brasília: O Instituto, set/dez. 2017.

FOCHI, P. Explorar e interagir com o mundo: os materiais na educação infantil. Disponível: https://www.researchgate.net/publication/319653399_Explorar_e_interagir_com_o_mundo_os_mat eriais_na_educacao_infantil/link/59b854af0f7e9bc4ca393777/download. Acesso 28I 22020

FRIEDMANN, A. Muito além do ouvido: o que é efetivamente escutar uma criança? Blog Lunetas, São Paulo, 19 fev. 2019. Disponível em: https://lunetas.com.br/escuta-infantil. Acesso em: 21 nov. 2020.

FRIEDMANN, A. A vez e a voz das crianças: escutas antropológicas e poéticas das infâncias. São Paulo: Panda Books, 2020.

GOBBATO, C.; BARBOSA, M. C. S. A artesania, o diálogo e a cooperação: uma perspectiva para a didática na Educação Infantil. Revista Poiesis, v. I3, n. 24. Florianópolis: Universidade do Sul de Santa Catarina, 2019. Disponível em: http://portaldeperiodicos.unisul.br/index.php/Poiesis/article/view/8254/4633. Acesso em: 20 abr. 2020.

HOLM, A. M. Eco Arte com crianças. 2. Reed. São Paulo: Ateliê Carambola, 2017.

KUHN, R.; CUNHA, A. C.; COSTA, A. R. Sem tempo para brincar: as crianças, os adultos e a tirania dos relógios. Revista Kinesis, 33. ed., v. I, Santa Maria, jan.jul. 2015.

LEITE, Maria Isabel. A criança desenha ou o desenho criança. A ressignificação da expressão plástica de crianças e a discussão crítica do papel da escrita em seus desenhos. In: OSTETTO, L. LEITE, M. I. Arte, infância e formação de professores: autoria e transgressão. Campinas, SP: Papirus, 2004. 
OSTETTO, L. E. Para encantar, é preciso encantar-se: danças circulares na formação de professores. Cad. Cedes, Campinas, vol. 30, n. 80, p. 40-55, jan.-abr. 2010. Disponível em: https://www.scielo.br/pdf/ccedes/v30n80/v30n80a04.pdf. Acesso em: 20 jan. 2021.

LEITE, Maria Isabel. OSTETTO, Luciana Esmeralda. Formação de professores: o convite da arte. In: OSTETTO, Luciana Esmeralda. LEITE, Maria Isabel. Arte, infância e formação de professores: autoria e transgressão. Campinas - SP: Papirus, 2004

PIORSKY, G. Brinquedos do chão: a natureza, o imaginário e o brincar. São Paulo: Peirópolis, 2016.

RINALDI, C. Diálogos com Reggio Emília: escutar, investigar e aprender. Tradução de Vania Cury. 5. ed. Rio de Janeiro/São Paulo: Paz e Terra, 2012.

SENNETT, R. Artesanía, tecnologia y nuevas formas de trabajo. Barcelona: Katz CCCB, 2013.

SENNETT, R. O artífice. 2. ed. Rio de Janeiro/São Paulo: Record, 2020.

STACCIOLI, G. Diário de Acolhimento na escola da infância. - Campinas, SP: Autores Associados, 2013 - Coleção Formação de Professores

VECCHI, Vea. Arte e criatividade em Reggio Emilia: explorando o papel e a potencialidade do ateliê na educação da primeira infância. Tradução Thais Helena Bonin. São Paulo: Phorte, 2017.

Recebido em: 0I de março de 202I.

Versão corrigida recebida em: 20 de abril de 2021.

Aceito em: 28 de julho de 2021 .

Publicado online em: 17 de setembro de 2021 .

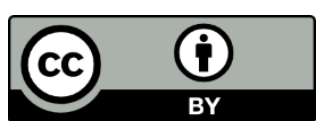

